\title{
Comment on "Reversible phase transition between amorphous and crystalline in Zr41.2Ti13.8Cu12.5Ni10Be22.5 under high pressure at room temperature" [Appl. Phys. Lett. 76, $2874(2000)]$
}

Jiang, Jianzhong; Gerward, Leif; Olsen, J. Staun

Published in:

Applied Physics Letters

Link to article, DOI:

$10.1063 / 1.1470697$

Publication date:

2002

Document Version

Publisher's PDF, also known as Version of record

Link back to DTU Orbit

Citation (APA):

Jiang, J., Gerward, L., \& Olsen, J. S. (2002). Comment on "Reversible phase transition between amorphous and crystalline in Zr41.2Ti13.8Cu12.5Ni10Be22.5 under high pressure at room temperature" [Appl. Phys. Lett. 76, 2874 (2000)]. Applied Physics Letters, 80(16), 3015-3016. https://doi.org/10.1063/1.1470697

\section{General rights}

Copyright and moral rights for the publications made accessible in the public portal are retained by the authors and/or other copyright owners and it is a condition of accessing publications that users recognise and abide by the legal requirements associated with these rights.

- Users may download and print one copy of any publication from the public portal for the purpose of private study or research.

- You may not further distribute the material or use it for any profit-making activity or commercial gain

- You may freely distribute the URL identifying the publication in the public portal 


\title{
Comment on "Reversible phase transition between amorphous and crystalline in $\mathrm{Zr}_{41.2} \mathrm{Ti}_{13.8} \mathrm{Cu}_{12.5} \mathrm{Ni}_{10} \mathrm{Be}_{22.5}$ under high pressure at room temperature" [Appl. Phys. Lett. 76, 2874 (2000)]
}

\author{
J. Z. Jiang and L. Gerward ${ }^{\mathrm{a})}$ \\ Department of Physics, Technical University of Denmark, Fysikvej 307, DK-2800 Kgs. Lyngby, Denmark \\ J. Staun Olsen \\ Niels Bohr Institute, Oersted Laboratory, University of Copenhagen, DK-2100 Copenhagen, Denmark
}

(Received 1 October 2001; accepted for publication 7 February 2002)

[DOI: $10.1063 / 1.1470697]$

In their recent letter, Sun et al. ${ }^{1}$ reported a reversible pressure-induced phase transition between the amorphous and crystalline state of the bulk metallic glass (BMG) $\mathrm{Zr}_{41.2} \mathrm{Ti}_{13.8} \mathrm{Cu}_{12.5} \mathrm{Ni}_{10} \mathrm{Be}_{22.5}$ at room temperature. Using in situ high-pressure x-ray diffraction and the energy-dispersive method in conjunction with synchrotron radiation, Sun et al. found that the bulk metallic glass partially crystallizes at 24 GPa upon compression, and that it reverts to the amorphous state upon decompression. All experiments were performed at room temperature. However, in our opinion, the authors have based their finding of this unusual behavior on the presence of one or two very weak peaks in their observed diffraction patterns (Sun et al., Fig. 1). ${ }^{2}$ Moreover, their experimental conditions are far from being optimized, perhaps as a result of the limited photon energy range of their synchrotron radiation source. Therefore, we have repeated the x-ray diffraction experiment under optimum conditions and, as the results will show, we observe no crystallization of the bulk metallic glass.

The white-beam, energy-dispersive method is based on the use of a fixed scattering angle, $2 \theta$, where $\theta$ is the Bragg angle. ${ }^{3}$ Sun et al. ${ }^{1}$ have used a rather large scattering angle, $2 \theta=22.8^{\circ}$, which means that possible diffraction features are occurring at photon energies less than $15 \mathrm{keV}$ (the broad amorphous peak is centered at $13.3 \mathrm{keV}$ ). At these low energies, there are problems with absorption in the diamonds of the high-pressure cell and in the sample itself. Another problem is caused by the presence of $\mathrm{x}$-ray fluorescence peaks $(\mathrm{Zr}$ $K \alpha$ and $\mathrm{Zr} K \beta$ ) in the same energy range.

Our high-pressure x-ray diffraction experiments were performed at the Hamburg Synchrotron Radiation Laboratory (HASYLAB). This is a powerful source and we have used radiation in the $20-70 \mathrm{keV}$ photon energy range. The diffractometer, working in the energy-dispersive mode, has been described elsewhere. ${ }^{4}$ High pressures were obtained in a Syassen-Holzapfel type diamond-anvil cell. The sample and a small ruby chip were enclosed in a hole of diameter 0.2 $\mathrm{mm}$ in an inconel gasket. For the pressure-transmitting me-

${ }^{a)}$ Electronic mail: gerward@fysik.dtu.dk dium, we have used a 16:3:1 methanol-ethanol-water mixture, i.e., the same medium as Sun et al. ${ }^{1}$ The pressure was determined by the ruby fluorescence method, using the nonlinear pressure scale of Mao et al. ${ }^{5}$ The Bragg angle, associated with each experimental run, was determined from a zero-pressure spectrum of powdered $\mathrm{NaCl}$ in the diamondanvil cell.

In our experiment, the scattering angle is $2 \theta=7.29^{\circ}$. At ambient pressure, the broad amorphous peak of the bulk metallic glass is found to be centered at $41.05 \mathrm{keV}$ (Fig. 1). The peak energy corresponds to a $d$ spacing of $2.37 \AA$ in good agreement with the value $2.36 \AA$ reported by Sun et al. ${ }^{1}$

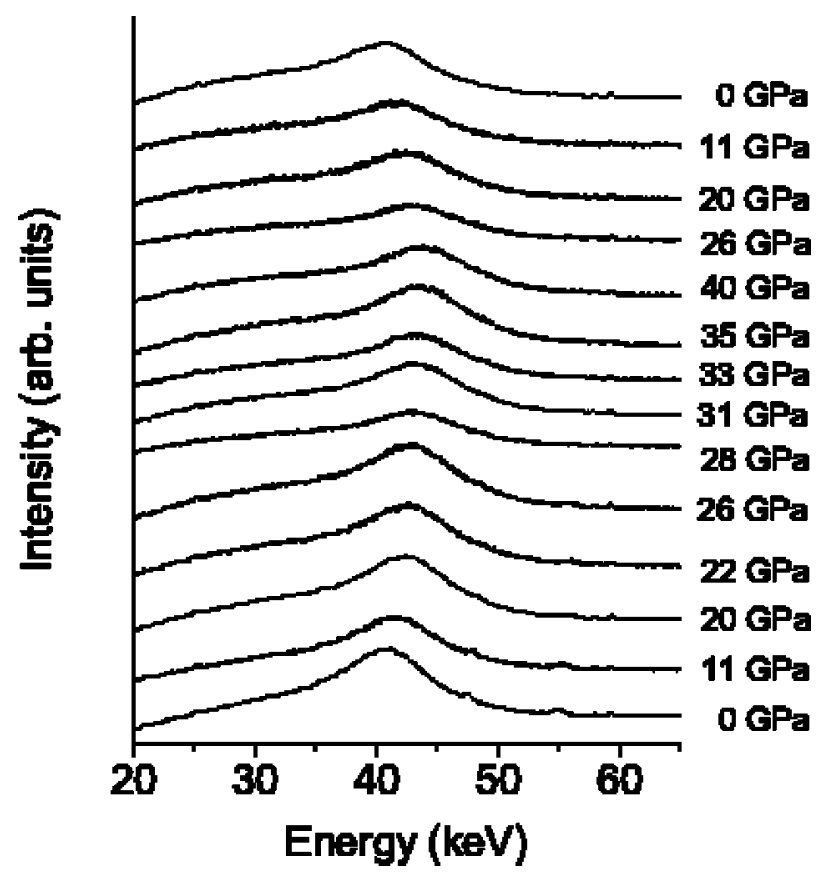

FIG. 1. In situ synchrotron radiation $\mathrm{x}$-ray diffraction patterns of $\mathrm{Zr}_{41.2} \mathrm{Ti}_{13.8} \mathrm{Cu}_{12.5} \mathrm{Ni}_{10} \mathrm{Be}_{22.5}$ bulk metallic glass under pressure at room temperature. Note the shift of the broad amorphous peak with pressure. The small peaks at about 47.5 and $54.8 \mathrm{keV}$ are inconel 111 and 200 lines due to the gasket. Also barely seen are the $\mathrm{W} K \alpha_{1}$ and $\mathrm{W} K \alpha_{2}$ peaks at 59.3 and $58.0 \mathrm{keV}$. They are caused by the slit system. The $\mathrm{Zr} K \alpha$ and $\mathrm{Zr} K \beta$ fluorescence peaks at 15.7 and $17.7 \mathrm{keV}$ have been eliminated by the lowerlevel discriminator of the multichannel pulse-height analyzer. 
Upon applying pressure, the amorphous peak is shifted to higher energies, corresponding to lower $d$ values, as expected. We have applied pressures up to $40 \mathrm{GPa}$, and in Fig. 1 we give some examples of the observed diffraction patterns. In particular, several diffraction patterns were recorded at pressures around $24 \mathrm{GPa}$. In none of our runs have we observed any sign of crystallization of the bulk metallic glass. Upon decompression, the amorphous peak is found to revert to its original position.

In conclusion, we are unable to reproduce the experimental findings of Sun et al. ${ }^{1}$ In particular, we have found no indications of any pressure-induced crystallization of the bulk metallic glass $\mathrm{Zr}_{41.2} \mathrm{Ti}_{13.8} \mathrm{Cu}_{12.5} \mathrm{Ni}_{10} \mathrm{Be}_{22.5}$ at room temperature.
This work was funded by the Danish Natural Sciences Research Council and the Danish Technical Research Council. We thank HASYLAB-DESY for permission to use the synchrotron radiation facility.

${ }^{1}$ L. L. Sun, W. K. Wang, D. W. He, W. H. Wang, Q. Wu, X. Y. Zhang, and Z. X. Bao, Appl. Phys. Lett. 76, 2874 (2000).

${ }^{2}$ Sun et al. (see Ref. 1) have also performed resistance measurements showing some interesting features, but in the present note we will comment on the x-ray diffraction results only.

${ }^{3}$ B. Buras and L. Gerward, in International Tables for Crystallography, 2nd ed., edited by A. J. C. Wilson and E. Prince (Kluwer, Dordrecht, 1999), Vol. C, p. 84.

${ }^{4}$ J. S. Olsen, Rev. Sci. Instrum. 83, 1058 (1992).

${ }^{5}$ K. H. Mao, P. M. Bell, J. W. Shaner, and D. J. Steinberg, J. Appl. Phys. 49, 3276 (1978) 